\title{
ESPIRAL
}

\section{Reseña del libro William Bunge. Las expediciones geográficas urbanas, 2017}

\author{
Review of the book William Bunge. The urban geographical expeditions, \\ 2017
}

\section{Resenha do livro William Bunge. Expedições geográficas urbano, 2017}

\section{Gabino Velázquez}

Centro de Estudios Antropológicos, Facultad de Ciencias Políticas y Sociales, UNAM

raxacame@gmail.com

Código ORCID: https://orcid.org/0000-0001-7503-625X

William Bunge. Las expediciones geográficas urbanas

Autor: Núria Benach

Editorial: Icaria, Colección Espacio críticos

ISBN: 978-84-9888-778-5

Edición: 2017

"Podéis sentaros y escribir un libro sobre los problemas, y aunque podéis llegar exactamente a las mismas respuestas a las que llegarían los estudiantes negros, nuestro libro irá a la biblioteca y será leído por personas de la misma profesión, pero nunca llegará a la gente"

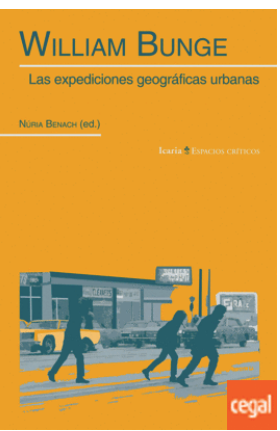
(p. 136). Con estas palabras Gwendolyn Warren, joven activista afroamericana, realiza una crítica audaz respecto a la investigación y la producción académica a inicios de 1970, cuyo mensaje trasciende hasta nuestros días.

El libro William Bunge. Las expediciones geográficas urbanas editado por Núria Benach, invita a reflexionar sobre un tema periférico en la ciencia geográfica, aquel sobre los compromisos asumidos por los geógrafos en la producción social del entorno vivido y habitado. Ello a través de dos figuras entrelazadas, una es el sujeto antiacadémico representado por William Bunge y la otra es la experiencia colaborativa de la Detroit Geographical Exploration and Institute (DGEI). Ambas figuras lograron conjuntar el saber de las aulas y los campus con el saber de las calles y llevar a cabo una propuesta democrática y crítica para el análisis y reconfiguración del espacio urbano. Si bien, la DGEI surgió por iniciativa de Bunge, la participación activa de diversos actores en distintas esferas permitió concretarla.

A diferencia de otros libros de la colección Espacios críticos, dirigida por Abel Albet y Núria Benach, el aquí reseñado y editado por la última, no presenta la trayectoria de 
un solo actor en relación dialéctica con su contexto social. ${ }^{1}$ La publicación apuesta por el trabajo colectivo de geógrafos académicos y geógrafos del pueblo (folk geographers) que dio forma a la DGEI. No resta protagonismo a William Bunge, por el contrario, lo posiciona como un geógrafo dedicado a la exploración verdaderamente humana de la superficie terrestre, es decir, al estudio inagotable de las formas de ocupación social y los cambios espaciales, cuyo fin es resolver, junto a los desposeídos, los problemas más vergonzosos de la especie humana.

La estructura de la obra que caracteriza a la colección, como es costumbre, aborda la trayectoria académica de William Wheeler Bunge (1928-2013) geógrafo teorético, que durante la convulsión social de finales de 1960 y principios de 1970, replantea sus necesidades académicas para hacer de la geografía una ciencia realmente útil y comprometida con la trasformación social. Fue el contexto social y político particular en Detroit el detonante para idear y fundar las expediciones geográficas urbanas. En este capítulo, Benach supera el mito del geógrafo convertido en taxista, para profundizar en su explosiva personalidad, en sus motivaciones e intencionalidades y posicionarlo como un referente del pensamiento geográfico crítico global.

La obra también incluye entrevistas y conversaciones con los expedicionarios como el mismo William Bunge, Ronald Horvath, Clark Akatiff y Gwendolyn Warren, cada una de ellas destaca las razones para emprender un proyecto de esa dimensión y las reflexiones sobre la puesta en práctica y su desenlace en 1972. La antología de textos traducidos por Núria Benach, ayudan a concebir la propuesta de la DGEI, así como los aciertos y problemas que enfrentaron sus participantes en el terreno del negocio académico. En los últimos tres artículos se impone la figura de Bunge para dar a conocer los aportes en el análisis de la configuración del espacio urbano, tanto en Detroit como en Toronto.

El texto inédito de la obra es escrito por R. Horvath, ahí rememora las prácticas llevadas a cabo por la DGEI, emanadas de una nueva forma de hacer investigación basada en una pedagogía crítica, emancipadora y liberadora. En la siguiente sección, la mano de Benach reactualiza a Wild Bill Bunge, no por la polémica alrededor de él, sino por los aportes de un geógrafo crítico de acción, preocupado por construir una ciencia geográfica integradora no dogmatica, matemática sí, pero no por ello menos crítica, una geografía de la supervivencia y de lo realmente humano. Su pensamiento y acción queda así inscrito: "después de todo, la función de los geógrafos no es sólo cartografía la tierra, sino cambiarla" (p. 93). Por último, la selección de bibliografía motiva a adentrarse al pensamiento crítico de la mano de un olvidado injustamente William Bunge y de la experiencia de las exploraciones geográficas.

La DGEI es una de las experiencias más fascinantes de la geografía respecto a la intervención y resolución de los conflictos sociales a través de propuestas colaborativas. Para sus participantes implicó reconocer la necesidad de aprender y ser partícipe de los procesos sociales, así como revertir las relaciones de poder entre investigador-investigado. Un experimento surgido del llamado a producir geografías radicales que constituye un esfuerzo adelantado a su tiempo, décadas después, su eco se encuentra con las geografías contemporáneas, sobre todo con aquellas experiencias de la disciplina basadas en la pedagogía crítica, la cartografía social y la investigación participativa y militante.

El libro es una ventana en la cual descubrimos la relevancia de la DGEI en su momento pero también como inspiración actual para aquellos geógrafos interesados en la investigación verdaderamente participativa, quienes deben tener presentes las palabras de Warren:

1 Otros libros de la colección incluyen a autores clásicos para el pensamiento crítico en geografía como: David Harvey, Doreen Masey, Edward Soja, Francesco Indovina, Franco Farinelli, Horacio Capel, Jean Pierre Garnier, Maria Dolors García, Neil Brenner, Neil Smith, Richard Peet, y Yi Fu Tuan. 
"Después de haber estado trabajando con aquel grupo de personas muy inteligentes y comprensivas, se hizo obvio que ellos sacaban mucho más de ello que nosotros [...] Pero nosotros, los jóvenes del barrio y la gente de Detroit, no nos beneficiábamos de la investigación. Porque era de naturaleza muy académica [...] Finalmente, tuvimos una reunión y dijimos que no íbamos a continuar [...] Y sin embargo, después de eso, ¿podéis creerlo? jvolvieron! Y nos dijeron que teníamos razón, “¿Qué es lo que queréis?»". (pp. 87-88)

Lo anterior marcó el inicio de una relación muy distinta donde no es suficiente reconocer las problemáticas sino abordar las necesidades reales, lo dejaría claro Bunge en la introducción del Journal of Human Exploration: Field notes 1, publicación ideada para mostrar los principales resultados de la expedición. En el breve tiempo de la experiencia, se dieron a conocer cuatro números en donde se establecen las bases propuestas por el mismo Bunge para justificar y llevar a cabo la exploración humana del planeta; además se publicó la propuesta más exitosa y democrática en la reorganización de distritos escolares, la cual mediante métodos y técnicas cuantitativas contrarresto una distribución espacial basada en la discriminación; contienen los mapas elaborados mediante la recolección de datos cuantitativos y cualitativos, en ellos mostraron la realidad espacial producto de la disposición estratégica de la injusticia social.

Un aspecto fundamental de la DGEI fue llevar los conocimientos geográficos de los profesores y estudiantes universitarios a las calles, mientras lograba que estudiantes negros se incorporaran a la universidad. Era un intercambio justo que funcionó los primeros años hasta encontrar a su principal enemigo en la misma institución universitaria que rechazaba la gratuidad del programa. Las nuevas condiciones establecidas por los administradores de la Michigan State University mostraron intereses distintos e incompatibles, Warren señala: "Para nosotros, se intentaba trasformar Detroit, pero para ellos se trataba de controlarnos políticamente" (p. 89).

Pero la DGEI fue más que artículos y mapas elaborados por y con la comunidad. A lo largo de la obra, los participantes dan cuenta de un potencial transformador inspirado en la Tesis 11 sobre Feuerbach: "Los filósofos no han hecho más que interpretar de diversos modos el mundo, pero de lo que se trata es de transformarlo" (Marx, 1974, p. 229). En términos del filosofo Sánchez Vázquez (1977), la DGEI debe concebirse como praxis, al promover actividades concretas basadas en un proyecto emancipador destinado a lograr la transformación urbana a diversas escalas, mediante la crítica pertinente y audaz sobre la situación concreta de la población negra en Detroit. Fue la experiencia de los desposeídos convertida en conocimiento el medio para la transformación social.

Al respecto, Ronald Horvath realiza, a cuatro décadas, un análisis de la investigaciónacción que guió las actividades y proyectos de las expediciones en apogeo. Usando la terminología actual, la DGEI puso en práctica 1) la acción directa enmarcada geográficamente, 2) la investigación geográfica emancipadora, 3) una pedagogía geográfica de liberación, 4) las llamadas contra-cartografías y, 5) el conocimiento situado del lugar. Para este expedicionario, lo radical no estuvo en formular nuevas teorías y métodos sino hacer que las existentes, junto a los mismos geógrafos, estuvieran a disposición de la comunidad.

Si bien hay obras del pensamiento geográfico que habían retomado a William Bunge (Gómez, Muñoz y Ortega, 1994), el esfuerzo de Núria Benach para recuperar su pensamiento y personalidad es relevante para la comunidad de habla hispana, pues amplia el conocimiento sobre un clásico de la geografía radical norteamericana. Su trayectoria es fascinante al ser pilar y transitar de la geografía teorética a la geografía radical por medio de obras como Theoretical geography y Fitzgerald: Geography of a Revolution. Pese a ello, ha sido un geógrafo marginal por no alinearse a las estructuras teóricas dominantes, incluida la marxista, ni a la rigidez de la institución académica, cuya consecuencia fue el aparente olvido. 
Por último, la obra de Benach sobre William Bunge y la DGEI repercute en la geografía actual por diversas razones analizadas en el libro. Una de ellas es la vigencia del pensamiento de Bunge focalizado en temas como la supervivencia humana, la crisis ambiental, los espacios urbanos desiguales y las consecuencias de esa producción en los desposeídos. Otra corresponde a la influencia actual de la DGEI, en el desarrollo de propuestas de intervención espacial multiescalar, en la construcción de mapas y atlas a partir de narrativas de "los de abajo" como medio de protesta frente a la lógica espacial del capital y en la puesta en práctica de innovadoras formas para la enseñanza geográfica más allá de la rígida esfera de la institución educativa, al utilizar pedagogías críticas emanadas de la educación popular.

Sin duda, el presente trabajo es una excelente oportunidad para acercarse a una de las vertientes originarias de la geografía radical cuya lectura desde la geografía crítica latinoamericana será útil para transformar la espacialidad de la región.

\section{Referencias.}

Benach, Núria. (2017). William Bunge. Las expediciones geográficas urbanas. Barcelona: Icaria.

Gómez, Josefina; Muñoz, Julio; y Ortega Nicolás (eds.). (1994). El pensamiento geográfico. Estudio interpretativo y antología de textos (de Humboldt a las tendencias radicales). Madrid: Alianza editorial.

Marx, Carlos. (1976). "Tesis de Feuerbach". Cuadernos políticos, 10. Recuperado el 12 de enero de 2020 de http://cuadernospoliticos.unam.mx/cuadernos/contenido/CP.10/CP.10.11. TesissobreFeurbach.pdf

Sánchez Vázquez, Adolfo. (1977). “La filosofía de la praxis como nueva práctica de la filosofía". Cuadernos políticos, 12, 64-68. Recuperado el 15 de enero de 2020 de http://www. cuadernospoliticos.unam.mx/cuadernos/contenido/CP.12/CP.12.6.SanchezVazquez.pdf 